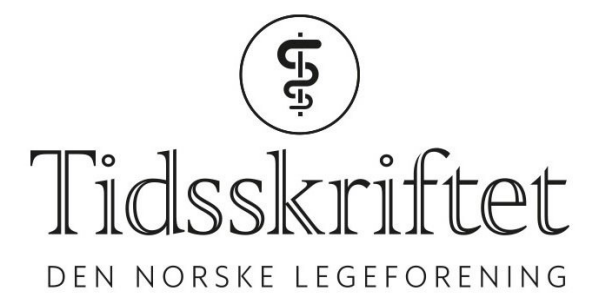

\title{
Vi har fått en stund her på jorden
}

INTERVJU

KARI TVEITO

E-post: Kari.tveito@tidsskriftet.no

Mange leger vet ikke at BRCA2-mutasjoner øker risikoen for pankreaskreft. Det gjorde ikke Cecilie Wium heller.

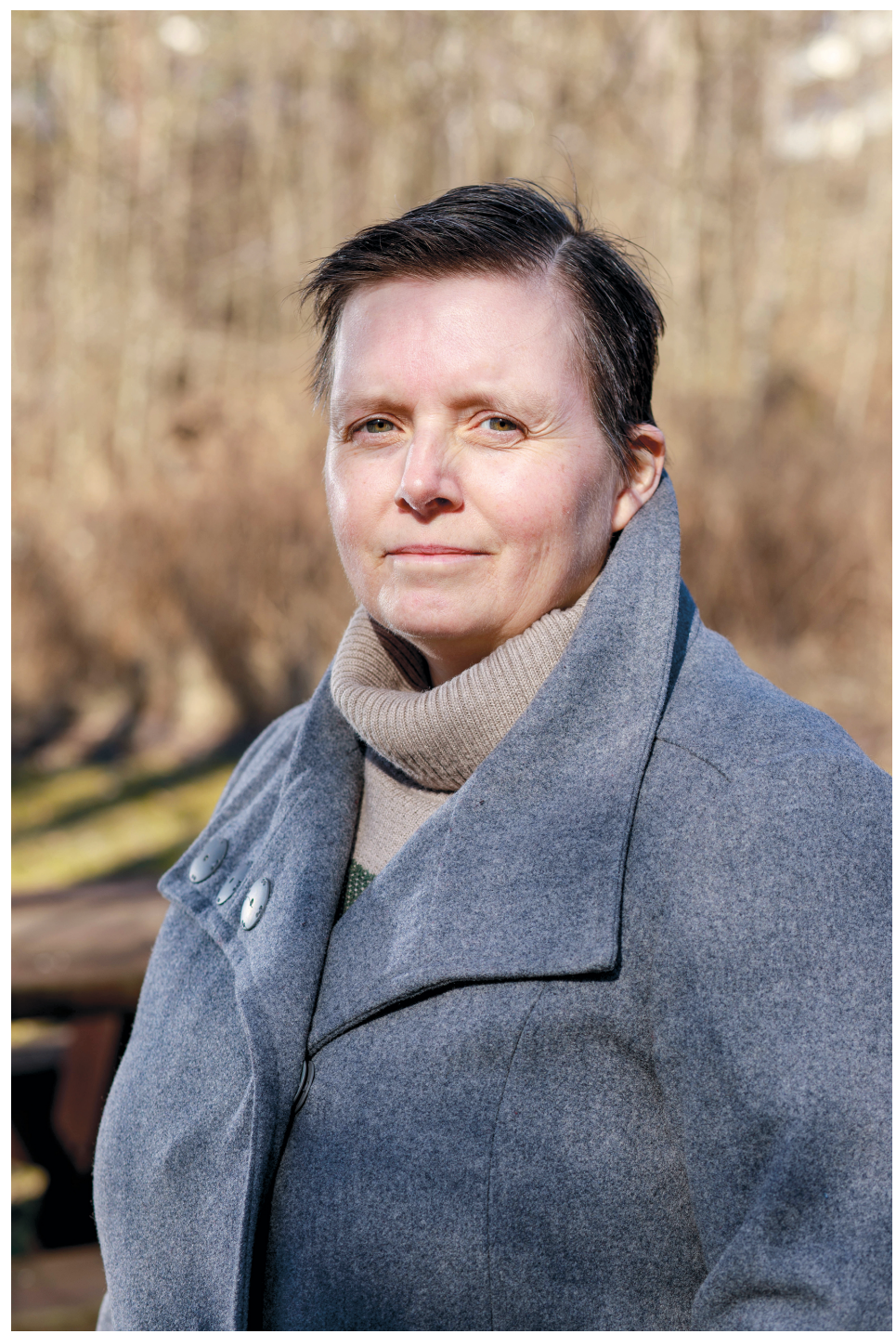

Foto: Niklas Lello

Fortsatt husker jeg bokomslaget. Den gule bakgrunnen, en oransje sol oppe i det høyre 
hjørnet, midt i bildet en staselig elefant omgitt av indere med turban.

- Veien til Agra ble en av oldemors mest populære barnebøker, forteller Cecilie Wium.

Aimée Sommerfelts fortelling, vakkert illustrert av Ulf Aas, kom ut i 1959. Boken handler om 13 år gamle Lalu og søsteren Maya på 7 år som er på vei fra Allahabad til Agra. Maya lider av en alvorlig øyesykdom, og søskenparet har hørt at sykdommen kan helbredes på sykehuset $\mathrm{i}$ Agra.

- Du har selv vært inne på tanken om å reise langt for å få behandling?

- Jeg har vurdert å dra til USA, ja, svarer overlegen.

- Men nå, med en pandemi, er ikke det et alternativ lenger, konstaterer hun nøkternt.

Frem til i fjor var Cecilie Wium den som tilsynelatende hadde tid til «alt». Venner og kollegaer beskriver endokrinologen som et arbeidsjern av de sjeldne, med en usedvanlig stor omsorg for pasienter så vel som kollegaer. Det er kanskje ikke tilfeldig at hun har vært tillitsvalgt gjennom hele karrieren.

- Hvorfor tar du på deg så mange verv?

- Jeg klarer ikke å ligge unna når jeg ser at vi kan finne bedre måter å jobbe på! Og så har jeg alltid hatt lett for å engasjere meg i ting.

Når man har mye å gjøre, blir man også mer strukturert, tror hun.

- Det merker jeg på ungene våre også. Selv om de er på svømmetrening stort sett hver dag, så får de unna leksene og gjør det bra på skolen.

Og foreldrene er med som svømmedommere.

- På den måten får man jo den beste plassen under stevnene, smiler Cecilie Wium.

Vi må screene høyrisikopasienter

De mange hobbyene har også inkludert seiling, kajakkpadling og dykking. Overlegens hjertebarn er likevel forskningen. Allerede som assistentlege begynte hun å undersøke hvordan man kunne bedre behandlingen av innvandrere fra Sør-Asia med diabetes. Arbeidet ble etter hvert til en doktorgrad og deretter utgangspunktet for et stort forskningsprosjekt som i 2017 ble bevilget 18 millioner av Forskningsrådet.

- Aner jeg en inspirasjon fra oldemor?

- Overlege Ingegerd Frøyshov Larsen på Lovisenberg Diakonale Sykehus var den som fikk meg interessert i dette. Men jeg har vokst opp med Aimées bøker og er nok blitt påvirket av hennes innsats mot diskriminering og for minoriteter generelt. Allerede på 1920-tallet var oldemoren opptatt av like rettigheter for kvinner og menn. Det har satt sine spor i den driftige familien.

- At jenter kan like godt som gutter, har jeg fått innprentet fra barnsben av.

\section{Til Grenoble}

Som fireåring debuterte Cecilie Wium som illustratør i Utposten, fagbladet for allmennmedisin og samfunnsmedisin.

- Far, som var distriktslege, startet bladet sammen med Harald Siem og Tore Rud. Når Utposten skulle ut, måtte hele familien trå til.

Da Cecilie Wium var sju år gammel, flyttet de fra Midsund utenfor Molde.

- Vi flyttet til Haugerud, for der hadde vi slekt. 


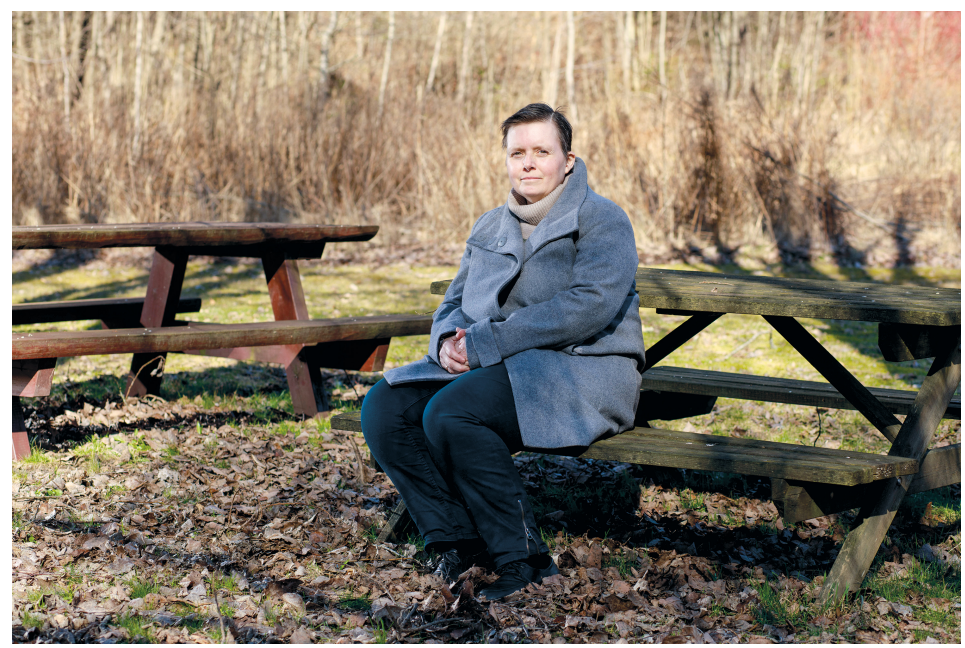

Cecilie Wiums tippoldefar, Aimée Sommerfelts far, var psykiater og startet sin egen klinikk på Trosterud gård i Oslo. Selv bodde Henrik Arnold Thaulow Dedichen i Trosterudvillaen, som i dag er vernet og står på Byantikvarens gule liste. På en av tomtene, skilt ut fra Trosterud gård etter at Dr. Dedichens asyl ble nedlagt i 196o-årene, vokste Cecilie Wium opp. Videregående tok hun på Oslo katedralskole, den eneste skolen i landet som kunne tilby latin som tredjespråk.

- Der var det nok oldefar som var inspirasjonskilden. Han var professor i gæliske språk.

Som både oldefaren og morfaren flyttet Cecilie til Frankrike for å studere.

- Da ville jeg i det minste ha lært meg et nytt språk hvis legeyrket ikke var for meg, tenkte jeg.

Medisinstudenten i Grenoble skjønte imidlertid raskt at hun hadde havnet på riktig hylle.

- Jeg har vel som mange andre leger et ønske om og behov for å hjelpe andre.

Aller best liker hun å jobbe med forebygging.

\section{Cecilie Wium}

\section{Født 1971}

Cand.med., Université Joseph Fourier, Grenoble, Frankrike 1997

Ph.d., Universitetet i Oslo 2014

Overlege ved Lipidklinikken, Oslo universitetssykehus 2014-

Startet forskningsprogrammet DIASA (DIAbetes hos Sør-Asiater) fra 2016

Tildelt 18 millioner fra Forskningsrådet til DIASA 2017

Spesialist i indremedisin og endokrinologi 2018

Postdoktor Universitetet i Oslo 2018

- På Lipidklikken, hvor jeg har vært overlege og medisinskfaglig ansvarlig de siste årene, behandler vi pasienter med arvelige lipidsykdommer. Mange av pasientene som kommer til klinikken med landsdekkende funksjon, har familiær hyperkolesterolemi.

- Ofte har vi hele familien inne til konsultasjon samtidig: barn, foreldre og besteforeldre.

Det å se at arbeidet forhindrer fremtidig sykdom, synes hun er spesielt meningsfylt.

- Når jeg ser effekten av det vi gjør, for eksempel at barn og barnebarn av foreldre og besteforeldre som har fått hjerte- og karsykdom i en bestemt alder, passerer den alderen og fortsatt er friske, da ... Hun stopper opp. Svelger en ekstra gang.

- Det er veldig godt å se. 


\section{En vanlig dag i april}

Det er et guffent vær den dagen dette intervjuet starter. Koronaepidemien har ennå ikke kommet til landet, men det er som det allerede hviler et mørke over byen. Gatene ser nakne og kalde ut, og det regner mistrøstig. Utenfor møtestedet treffer jeg endokrinologen, som jeg tidligere har jobbet sammen med. Hun strever litt med balansen på vei inn.

- Det er en bivirkning etter cellegiften, forteller hun.

Men ellers er Cecilie Wium akkurat som jeg husker henne. Styrken i stemmen, det gode og trygge blikket, ingenting har forandret seg.

- Hvordan fikk du vite at du er syk?

- Det var i april i fjor. Jeg gikk til fastlegen med noe jeg trodde var bagatellmessige magesmerter.

Neste dag fikk hun svar på blodprøvene og kunne konstatere normale funn på alle. Men fastlegen hadde også henvist henne til ultralyd. Den tok hun innimellom pasientkonsultasjonene på sykehuset.

- På ultralydundersøkelsen så røntgenlegen at noe ikke var som det skulle med leveren.

Hun fikk CT-undersøkelse med det samme, og etter lunsj tikket bildene inn på hennes egen datamaskin.

- Jeg skjønte med en gang hva som feilte meg.

Hun søkte tilflukt hos en god kollega over gangen som trøstet så godt hun kunne. Men etter en stund, forteller kollegaen, tørket Cecilie tårene og sa at hun trengte å være litt alene. Der, på kontoret, bestemte overlegen seg for hvem hun skulle ta kontakt med og hvor hun ville behandles. Så kjørte hun hjem til Bærum for å fortelle sin ektemann, 11 år gamle datter og 14 år gamle sønn at hun hadde fått pankreaskreft med spredning.

\section{Screening for pankreaskreft}

Cecilie Wium visste at det fantes en BRCA2-mutasjon i familien.

- Mormor og hennes søster fikk begge brystkreft, fikk behandling og levde i mange år etterpå. Deres mor, Aimée Sommerfelt, døde av ovarialkreft da hun var i 8o-årene. Så jeg oppfattet ikke min situasjon som så alvorlig. Min mor har aldri vært syk, og jeg tenkte at mutasjonen kanskje ikke var blitt overført til vår gren av familien.

BRCA2-mutasjoner øker risikoen for arvelig bryst- og ovarialkreft hos kvinner og prostatakreft hos menn. Alle med mutasjonen får tilbud om genetisk veiledning. Kvinner anbefales noen ganger å fjerne bryster og eggstokker for å minske sykdomsrisikoen.

- Jeg har hatt en plan om å genteste meg etter hvert, jeg også, og å bli operert om nødvendig. Det Cecilie Wium imidlertid ikke visste, er at BRCA2-mutasjoner også øker risikoen for pankreaskreft.

- Det som er vondt å tenke på, er at ting kanskje kunne sett annerledes ut om jeg bare hadde kjent til det.

Når du har kort tid igjen å leve, vil du gjerne oppleve så mye som mulig

Flere land anbefaler screening for pankreaskreft hos pasienter med BRCA-2-mutasjoner. Men i Norge blir ikke pasientene informert om risikoen.

- Det å underslå informasjon som kan være livsviktig, synes jeg er svært etisk betenkelig.

Argumentet fra fagmiljøet har vært, slik hun har forstått det, at slik informasjon vil skape unødig bekymring.

- Det er jo alltids et argument, men man må også veie det opp mot konsekvensene ved ikke å informere. Når det gjelder pankreaskreft, så er det dødsdom. 
Hun må ta en pause for å tørke tårene. Så fortsetter hun ufortrødent.

- Stort sett alle kreftformer har man i dag et behandlingstilbud for. Mye kan man bli frisk av. Men ikke pankreaskreft. Eneste mulighet er å avsløre kreften tidlig, før man har symptomer.

Cecilie Wium mener at vi burde starte et nasjonalt screeningprogram for pankreaskreft ved bestemte arvelige mutasjoner.

- Vi må screene høyrisikopasienter. Dataene vi da får, må vi også benytte til forskning.

Det vanskelige med pankreaskreft er at kreftcellene "gjemmer seg», og så hemmer de immunforsvaret.

- Det er nesten ingenting som biter på den.

Kanskje er det nettopp dette som har gjort at kreftformen i mange år har vært en "glemt» sykdom.

- Interesseorganisasjonen Pancreaskreft Nettverk Norge ble først startet i 2016. Når levetiden er så kort, er det ikke så mange som har ork til å engasjere seg.

Cecilie Wium orker, og hun er også med i Kreftforeningens kampanje Krafttak mot kreft, som i år som i fjor fokuserer på pankreaskreft.

\section{Korona}

Cecilie Wium er ikke den som bekymrer seg unødig. Hun sover godt om natten.

- Det lærte jeg meg da jeg holdt på med doktorgraden min.

Etter flere år som klinisk stipendiat og oppskattet lektor ved Aker sykehus, jobbet hun fulltid som kliniker og forsket til sent på kveld. Da gjaldt det å sove når hun kunne.

- Siden har jeg aldri hatt søvnproblemer, sier hun og ler den karakteristiske smittende latteren sin.

- Det kommer godt med nå.

Men hun er mer sliten enn før og merker at hun må rasjonere med kreftene.

- Jeg har dessverre måttet sykmelde meg fra overlegestillingen min.

Men når hun er innom arbeidsplassen, som hun ofte er, gir hun gjerne råd til kollegaer som trenger det og bidrar der hun kan.

- Lipidklinikken har alltid stilt opp for meg, og jeg er veldig glad i alle der.

Det er ikke få av klinikkens julebord og sommeravslutninger som har blitt holdt hjemme hos henne. Og ektemannen?

- Han har ikke alltid blitt spurt, smiler hun lurt.

- Men han har tatt det sporty når han har kommet hjem til et kjøkken fullt av gjester som lager mat i fellesskap.

Det var også vemodig å måtte gi fra seg hovedansvaret for det store diabetesprosjektet DIASA til samarbeidspartner og tidligere veileder, Kåre Birkeland.

- Men jeg er veldig glad for at han sa ja med det samme.

Postdoktoren jobber fortsatt mye med prosjektet.

- Jeg kan jo ikke sitte med hendene i fanget heller, bare fordi jeg har blitt syk.

Familien prøver å holde mest mulig på en normal hverdag. Det gir styrke, tror Cecilie Wium. I tillegg er det godt å få støtte fra kollegaer og venner. Hun valgte tidlig å dele med andre hva som hadde skjedd. Etter hvert tok det for mye tid å fortelle alt til alle, så nå har hun en egen Facebook-gruppe hvor hun legger ut oppdateringer. At hun kanskje kan bidra til å informere andre om faren for pankreaskreft ved BRCA2-mutasjoner, føles også meningsfylt. 
- En slektning av meg testet seg på grunn av det som skjedde. Det viste seg at hun hadde brystkreft. Jeg er veldig glad for at det ble oppdaget i tide.

Én ting er det likevel vanskelig å forsone seg med: at det skulle komme en pandemi.

- Hvis jeg blir smittet av koronavirus, så kan det bli veldig alvorlig.

Hun er også bekymret for at det kan bli vanskelig å få annen nødvendig helsehjelp.

- Fastlegen min, onkologen, min palliative onkolog, jeg kan ikke få rost dem nok. Men jeg er redd for at det i et overbelastet system kan skje glipper.

Som tillitsvalgt har hun vært opptatt av tidspresset som leger opplever, også i den vanlige hverdagen.

- Gode rammevilkår og nok tid til å utføre alle oppgaver skikkelig er utrolig viktig. Det har jeg erfart både som lege og pasient.

Det er også sårt å tenke på at de kanskje ikke får gjennomført reisene som familien har planlagt denne våren.

- Når du har kort tid igjen å leve, vil du gjerne oppleve så mye som mulig. Leve livet fullt ut.

Vi blir stille. Sitter sammen. Tørker tårer med servietter. Jeg kommer til å tenke på «Gabriellas sång», fra den livsbejaende publikumssuksessen «Så som i Himmelen». Jag vill känna att jag lever, synger Gabriella. All den tid jag har.

- Vet du forresten at jeg er gift nå, bryter Cecilie Wium stillheten.

- Vi skulle egentlig gifte oss sommeren 2019, men vi fremskyndet det.

Bryllupet sto to uker etter at hun fikk påvist kreft, og før de verste smertene satte inn.

- Onsdag tok forloverne mine meg med for å finne kjole, fredag var den ferdig sydd.

Lørdag ettermiddag var det bryllup på Høvik i et hjem fylt opp med venner og familie.

Cecilie Wium ser på meg med et ansikt som stråler. Øynene har fått en egen glød.

- Det ble en fantastisk dag.

Publisert: 17. april 2020. Tidsskr Nor Legeforen. DOI: 10.4045/tidsskr.20.0271

(C) Tidsskrift for Den norske legeforening 2020. Lastet ned fra tidsskriftet.no 